\title{
TRAINING IMPLEMENTATION HEALTHY HEART Gymnastics in LANS IN PUSKESMAS RUMBAI COAST OF PEKANBARU
}

\author{
Rina Yulviana, SKM, M.Kes, Syukaisih, SKM, M.Kes \\ Email: rinayulviana@htp.ac.id
}

\begin{abstract}
Healthy heart exercise is a sport that takes a lot of oxygen. Healthy heart exercise aims to increase blood flow throughout the body in 24 hours. Especially as you get older, your heart's performance will decrease.

Healthy heart exercise is made specifically to make a healthy heart, so the movements that are pleasing to a healthy heart stimulate the heart to take as much oxygen as possible, so that the oxygen needs in the body are met. The heart is said to be in good condition if the pulse is normal and stable, because improvement in the pulse is also one of the goals of healthy heart exercise. The method used in this community service has two stages. The first is a question and answer lecture using an infocus and a leaflet. The second stage demonstrates using a model in which the model provides a direct example of practicing healthy heart exercise to the elderly, after it is demonstrated, the elderly are evaluated to directly practice healthy heart exercise. The results of this community service activity show that the knowledge of the elderly about the importance of Healthy Heart Exercise and the elderly want carry out Healthy Heart Exercises at home which are held every day. It is suggested that the Puskesmas can carry out activities and socialize it to the elderly.
\end{abstract}

Keywords: Healthy Heart Exercises, Elderly, Puskesmas Rumbai Pesisir

\begin{abstract}
Abstrak
Senam jantung sehat sehat adalah olaraga yang banyak menghirup oksigen. Senam jantung sehat bertujuan untuk memperlancar aliran darah keseluruh tubuh dalam 24 jam. Apalagi saat usia bertambah, performa jantung akan semakin menurun.

Senam jantung sehat memang dibuat khusus untuk membuat jantung sehat, maka gerakangerakan yang terdapat disenan jantung sehat memacu jantung untuk mengambil oksigen sebanyak-banyaknya, agar kebutuhan oksigen didalam tubuh terpenuhi. Jantung dikatakan dalam kondisi baik jika denyut nadi normal dan stabil, karena itu perbaikan denyut nadi juga menjadi salah satu tujuan senam jantung sehat. Metode yang digunakan dalam pengabdian masyarakat ini ada dua tahap yang pertama ceramah tanya jawab menggunakan infokus dan leaflet. Tahap kedua mendemonstrasikan menggunakan model dimana model tersebut memberikan contoh langsung mempraktekkan Senam jantung sehat kepada Lansia, setelah didemontrasikan maka lansia dievaluasi untuk mempraktekkan langsung Senam jantung sehat.. Hasil dari kegiatan pengabdian masyarakat ini dapat bahwa meningkatnya pengetahuan lansia akan pentingnya Senam Jantung Sehat dan lansia mau melaksanakan Senam Jantung Sehat di rumah yang dilaksanakan setiap harinya. Disarankan agar pihak Puskesmas dapat melaksanakan kegiatan serupa dan dapat mensosialisasikan kepada lansia.
\end{abstract}

Kata Kunci : Senam Jantung Sehat, Lansia, Puskesmas Rumbai Pesisir 


\section{PENDAHULUAN}

Lansia (55-65 tahun)

merupakan suatu bagian dari tahap perjalanan hidup manusia yang keberadaannya senantiasa harus diperhatikan. Pandangan sebagian masyarakat yang menganggap lansia sebagai manusia yang tidak mampu, lemah, dan sakit-sakitan menyebabkan mereka memperlakukan lansia sebagai manusia yang tidak berdaya, sehingga segala aktivitasnya sangat dibatasi (Menuh, 2007).

Penggolongan lansia menurut Depkes menjadi tiga kelompok yakni :

1. Kelompok lansia dini (55-64 tahun), menrupakan kelompok yang baru memasuki lansia

2. Kelompok lansia (65 tahun keatas)

3. Kelompok lansia resiko tinggi, yaitu lansia yang berusia lebih dari 70 tahun.

Senam jantung sehat sehat adalah olaraga yang banyak menghirup oksigen. Senam jantung sehat bertujuan untuk memperlancar aliran darah keseluruh tubuh dalam 24 jam.
Apalagi saat usia bertambah, performa jantung akan semakin menurun.

Senam jantung sehat memang dibuat khusus untuk membuat jantung sehat, maka gerakan-gerakan yang terdapat disenan jantung sehat memacu jantung untuk mengambil oksigen sebanyak-banyaknya, agar kebutuhan oksigen didalam tubuh terpenuhi. Jantung dikatakan dalam kondisi baik jika denyut nadi normal dan stabil, karena itu perbaikan denyut nadi juga menjadi salah satu tujuan senam jantung sehat.

Sering kali keberadaan lanjut usia dipersepsikan secara negative, dianggap sebagai beban keluarga dan masyarakat sekitar. Kenyataan ini mendorong semakin berkembangnya anggapan bahwa tua semakin banyak masalah kesehata, lanjut usia juga cenderung dipandang masyarakat tidak lebih dari sekelompok orang yang sakit-sakitan. Persepsi ini muncul karena memandang lanjut usia yang bergantung kepada kepada orang lain serta sakitsakitan (Sidiarto, 2002).

Melihat kondisi yang telah dipaparkan diatas sangat jelas 
dibutuhkan perhatian dan pelayanan kesehatan yang intensif dan berkesinambungan, yang harus diberikan kepada penduduk lanjut usia agar lansia dimasa tuanya menjadi lansia yang sehat, berguna bagi masyarakat sekitarnya, merasa bahagia dan sejahterah secara fisik. Senaman jantung sehat berpengaruh positif terhadap penderita hipertensi karna dapat menurunkan tekanan sistolik dan diastolic dengan intensitas senam sebanyak 3 kali seminggu dan lama latihan 20-60 menit sekali latihan (Cerika, 2008).

Penduduk antar sensus (Supas) yang dialukan badan pusat statistic (BPS),lansia di propinsi riau pada tahun 2005 berjumlah sekitar 173.606 jiwa atau 3,8 persen dari jumlah penduduk 4.563.406.Pada tahun 2010 jumlah lansia di Riau bertambah menjadi 225.353 jiwa atau 4,1 persen dari total penduduk riau,5.538.367.dari jumlah tersebut terdapat 80.602 jiwa lansia tinggal di perkotaan dan 144.751 jiwa lansia tinggal dipedesaan.dari kedua daerah tersebut lansia perempuan lebih banyak disbanding lansia laki-laki (Sensus Penduduk 2010). Data lansia yang berkunjung ke Puskesmas Rumbai Pesisir Pekanbaru dari bulan juli-oktober adalah sebanyak 50 orang lansia

Berdasarkan Survey awal yang dilakukan terhadap 10 orang Lansia yang ada di Puskesmas Rumbai Pesisir Pekanbaru maka diperoleh ada lansia yang memiliki pengetahuan Kurang tentang Senam jantung sehat, 10 orang Lansia yang memiliki pengetahuan Baik tentang Senam jantung sehat.

Berdasar dari latar belakang diatas penulis tertarik untuk melakukan Pelatihan Pelaksanaan Senam jantung sehat Pada Lansia di Puskesmas Rumbai Pesisir Pekanbaru ini untuk mengetahui apakah ada hubungannya pengetahuan lansia dengan pelaksanaan Senam jantung sehat tersebut.

\section{METODE PENERAPAN}

1. Demonstrasi

Metoda yang demonstrasi yang digunakan dalam pengabdian ini dengan menggunakan model dimana model tersebut memberikan contoh langsung mempraktekkan Senam jantung sehat kepada Lansia, setelah didemontrasikan maka 
lansia dievaluasi untuk mempraktekkan langsung Senam jantung sehat.

2. Ceramah interaktif

Bentuk kegiatan dilakukan berupa penyuluhan dengan menggunakan alat bantu infocus dan leaflet serta brosur diberikan kepada lansia. Setelah diberikan pengetahuan tentang Senam jantung sehat maka akan dibuka forum diskusi tanya jawab.

\section{HASIL DAN PEMBAHASAN}

\section{A. Hasil Kegiatan}

Kegiatan pengabdian masyarakat tentang pelatihan senam jantung sehat pada lansia, dilakukan kunjungan pertama pada tanggal 6 Agustus 2018 untuk melakukan pelatihan pada instruktur senam jantung sehat pada lansia. Dari hasil pelatihan, didapatkan instrukstur mengerti dan mampu melakukan senam jantung sehat. Kemudian pada hari selasa tanggal 7 Agustus 2018, dilakukan kegiatan senam jantung sehat di Puskesmas Rumbai Pesisir, dengan di pandu oleh instruktur senam yang telah ditunjuk untuk melatih para lansia dalam melakukan senam jantung sehat. Kegiatan senam jantung sehat ini diikuti sebanyak 43 orang lansia wanita. Sebelum melakukan senam jantung sehat terlebih dahulu dilakukan penghitungan denyutnadi serta pengukuran tensi pada lansia, dan didapatkan hasil yaitu denyut nadi normal sedangkan tekanan darah sebagian lansia mengalami hipertensi sedang dan berat. Denyut nadi merupakan irama dari detak jantung yang dapat diraba pada bagian-bagian tubuh tertentu. Pada lansia denyut nadi normal waktu istirahat, berkisar 60- 80 kali per menit. Hipertensi didefinisikan dimana kondisi tekanan darah sistolik sama atau lebih dari $140 \mathrm{mmHg}$ dan tekanan diastolik lebih tinggi dari 90 mmHg (Padila, 2013).

Setelah melakukan senam jantung sehat lansia dapat mekasanakan kembali senam jantung sehat sampai berhasil, lansia dapat merelaksasi tubuh setelah senam jantung sehat, lansia dapat mencegah atau melambatkan kehilangan fungsional setelah senam jantung sehat, lansia merasa berbahagia, senantiasa bergembira, bisa tidur nyenyak dan pikiran tetap segar. 
Selanjutnya dilakukan kembali

pengecekan denyut nadi dan

pengukuran tensi. Didapatkan

hasil bahwa seluruh denyut nadi

lansia lebih cepat dari denyut nadi saat istirahat.Dan tidak terdapat penurunan tekanan darah yang signifikan, hal ini disebabkan bahwa lansia tidak rutin dalam melaksanakan senam jantung sehat. Menurut Suhardo (2001), prinsip senam jantung sehat yaitu minimal 3 kali dan optimal 5 kali seminggu. Pada saat pelaksanaan senam jantung sehat, tampak keantusiasan lansia dalam mengikuti kegiatan senam jantung sehat. Sekitar $90 \%$ peserta senam dapat mengikuti gerakan kegiatan senam jantung sehat.

Selain melakukan senam jantung sehat, dilakukan juga penyuluhan tentang senam jantung sehat dan manfaat senam jantung sehat bagi lansia. Didapatkan hasil bahwa setelah diberikan materi melalui diskusi dan tanya jawab, para lansiamengerti dan mampu menjawab pertanyaan tentang senam jantung sehat serta manfaatnya.

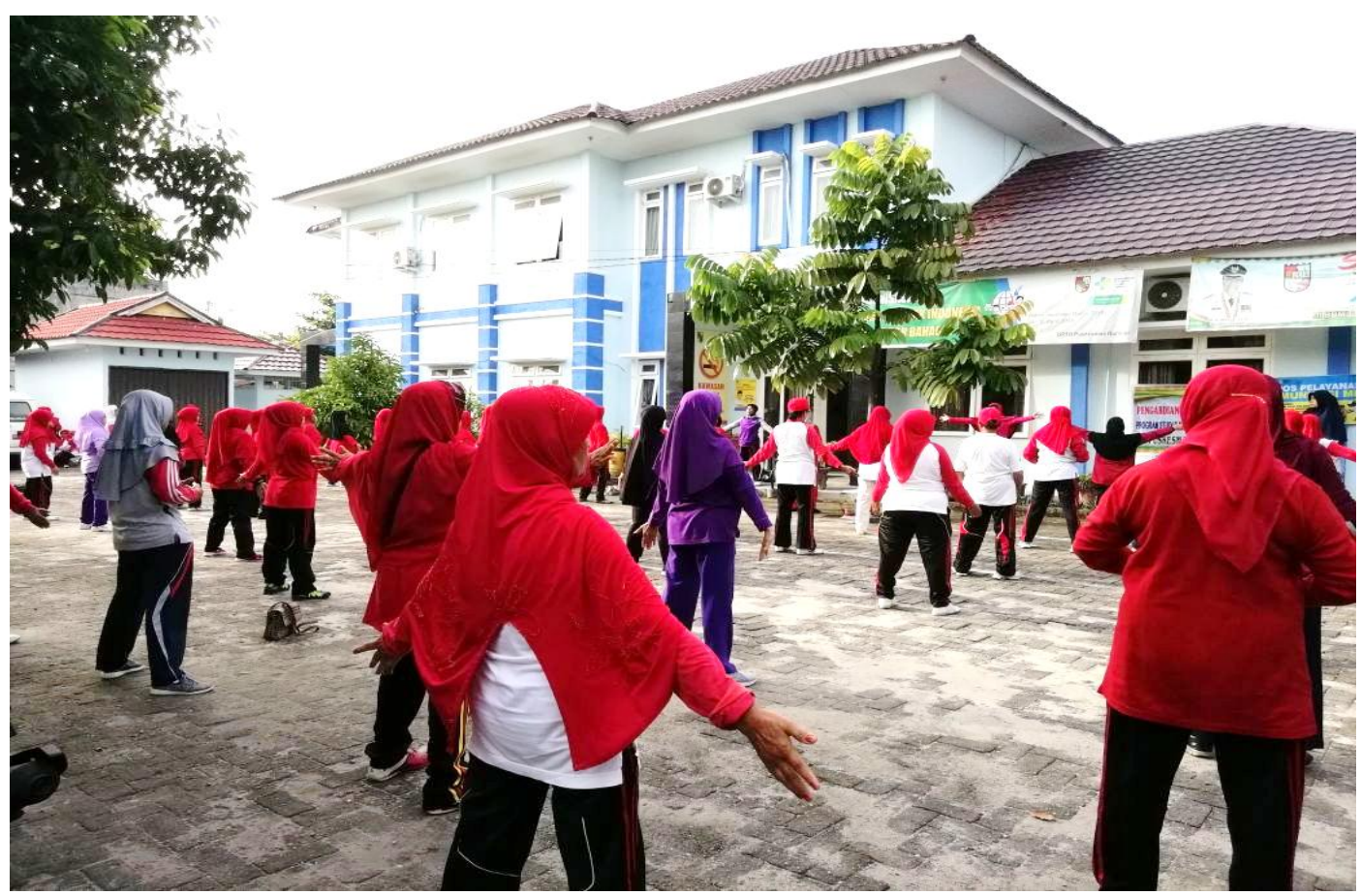



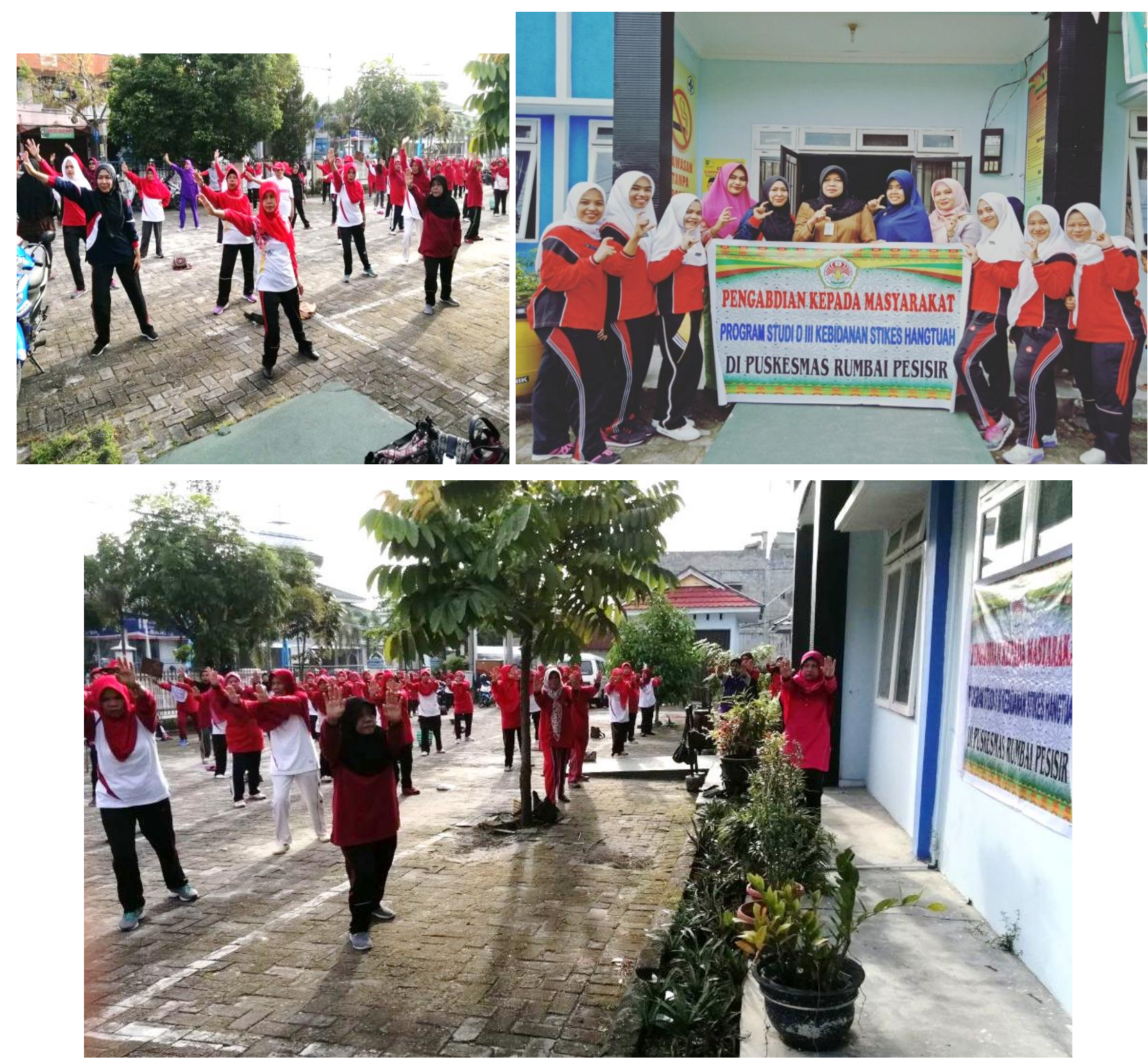

B. PEMBAHASAN

Salah satu usaha untuk meningkatkan kesehatan lansia adalah dengan mengadakan senam jantung sehat. Senam jantung sehat merupakan olahraga ringan dan mudah dilakukan, tidak memberatkan pada lansia. Aktifitas olahraga ini tidak membutuhkan alat, tenaga dan waktu yang banyak sehingga cocok sebagai pengisi waktu luang.
Senam jantung sehat pada lansia dapat dilaksanakan kembali oleh lansia sampai berhasil, sehingga lansia dapat merelaksasi tubuh setelah senam jantung sehat, lansia dapat mencegah atau melambatkan kehilangan fungsional setelah senam jantung sehat, serta lansia merasa berbahagia, senantiasa bergembira, bisa tidur nyenyak dan pikiran tetap segar 
Dalam pelaksanaan senam jantung sehat yang telah dilakukan, semua pesertanya adalah ibu-ibu (lansia wanita). Sedangkan bapakbapaknya (lansiapria) tidak ada satupun yang mengikuti senam jantung sehat. Hal ini dikarenakan kurangnya minat serta pengetahuan masyarakat tentang pentingnya senam jantung sehat untuk para lanjut usia. Padahal sesungguhnya dengan mengikuti senam jantung sehat, efek minimalnya adalah menjaga kondisi fisik dan metabolisme pun menjadi baik. Senam Jantung Sehat ini juga dapat melenturkan otot dan sendi, dapat menghilangkan kekakuan otot serta menambah kekuatan otot tangan dan kaki. Selain itu, senam jantung sehat dapat menyehatkan jantung yaitu melancarkan aliran darah. Fungsi ini sangat penting untuk menjaga kesehatan jantung sebab bisa mencegah terjadinya penyakit stroke, jantung koroner, membantu mengurangi penyumbatan pembuluh darah yang diakibatkan oleh timbunan lemak dan kolesterol yang kini sudah menjadi momok karena gaya hidup yang tidak sehat.

\section{KESIMPULAN}

Dari kegiatan pengabdian masyarakat ini dapat disimpulkan bahwa :
1. Lansia dapat melaksanakan senam jantung sehat sampai berhasil.

2. Lansia dapat merelaksasikan tubuh setelah melakukan senam jantung sehat.

3. Lansia dapat mencegah atau melambatkan kehilangan fungsional setelah senam jantung sehat.

4. Lansia merasa berbahagia, senantiasa bergembira, bias tidur nyenyak, pikiran tetap segar.

\section{DAFTAR PUSTAKA}

1. Bandiyah, Siti. 2009. Lanjut Usia dan Keperawatan Gerontik. Yogyakarta: Nuha Medika.

2. Direktorat Bina Gizi Masyarakat Depkes RI, 2008. Petunjuk Menyusun Menu Bagi Usia Lanjut. Departemen Kesehatan, Jakarta

3. Hartono, Andry. 2008. Gizi Bagi Manula,Kompas, 18 Agustus.

4. Kartari DS, 2009. Manusia usia lanjut. Disampaikan dalam Diskusi Ilmiah Badan Litbangkes Depkes RI, Jakarta, 30 Januari.

5. Kusmana, Dede. 2011. Olahraga pada usia Lanjut. Simposium menuju hidup sehat pada usia Lanjut. Bogor, 7 November.

6. Nugroho, Wahjudi, Keperwatan Gerontik. Jakarta: EGC 
7. Soekidjo, Notoadmodjo. 2010. Metodologi Penelitian Kesehatan. Jakarta: PT Rineka Cipta.

8. Https: // Yuliakusumadewi. Wordpress.com/2012/03/12/Penge rtian lansia

9. Machfoedz, I. 2010. Metode Penelitian Kuantatif \& Kualitatif Bidang Kesehatan Keperawatan, Kebidanan, Kedokteran. Yogyakarta:

Fitramaya.

10. Kushariyadi. 2010. Asuhan Keperawatan Pada Klien Lanjut Usia. Jakarta: Salemba Medika.
11. Tri Widianti, A \& Proverawati, A. 2010. Senam kesehatan. Yogyakarta: Nuha Medika.

12. Widfyantoro, Putra. 2012. Hubungan antara Senam lansia dan Range Of Mation (ROM) Lutut Pada Lansia, Fakultas Kedokteran Universitas Islam Sultan Agung: Semarang

13. Paryanti, yani. 2011. Hubungan Antara Pengetahuan Lanjut Usia Tentang Senam dengan Keaktifan Dalam Mengikuti Senam, Fakultas Ilmu Kesehatan Unuversitas Muhammadiyah: Sukarta 